Resenha:

PINKER, Steven. Como a mente funciona. Companhia das Letras, SP, 1998.

\title{
Computador neural que identifica objetivos e estratégias para obtê-los
}

\section{Maria Isabel Timm ${ }^{1}$}

O trabalho de Pinker (1998), no livro Como a mente funciona, é exaustivo e minucioso. $\mathrm{O}$ autor se debruça sobre múltiplos aspectos do processamento mental humano, suas causas e características genéticas, moldadas pela seleção natural, bem como nas conseqüências desse tipo de processamento na formação das relações humanas, da sociedade, das culturas, das religiões, da arte, entre outras. Apesar dessa abordagem exaustiva, o autor não trata especificamente, em nenhum momento, da mente do engenheiro ${ }^{2}$ ou de qualquer outra profissão em especial. Todas as suas considerações são generalizadoras, para toda a espécie humana, a respeito de como a mente humana processa informações, seguindo um padrão que tem raízes ancestrais, destinado a viabilizar a sobrevivência dos seres humanos ao longo da competição darwinista que travou com outros humanos, com animais e plantas existentes no ambiente. Esse padrão está substancialmente gravado em um programa (software mental humano), transmitido geneticamente e adaptado (às vezes mal adaptado, segundo o autor) à complexidade da vida contemporânea.

A principal matriz desse programa é a identificação de objetivos relacionados à necessidade de sobrevivência, diz Pinker, e sua operação básica consiste no desenvolvimento de estratégias para realizá-los. Esse foi o impulso primeiro, ainda segundo o autor, que viabilizou o enfrentamento de obstáculos de toda sorte, levando a espécie a desenvolver seu nicho de sobrevivência pela capacidade de processar informações de forma inteligente. Nesse processo, aprendeu a desenvolver estratégias de cooperação, baseadas em reciprocidade mútua. Aprendeu a desenvolver suas habilidades inatas para operar sobre o mundo (uma matemática intuitiva, uma noção intuitiva de objeto, etc.) e acabou chegando ao Século XXI com um repertório estruturado de conhecimentos aplicáveis ao mesmo velho objetivo - sobrevivência. Esse repertório cresceu de forma considerável (constituindo-se de módulos dentro de módulos de conhecimento) e diversificou-se nas formas da Física, da Matemática, da Biologia, Psicologia e da Engenharia contemporâneas, devidamente estruturadas.

Um resumo dos principais pontos do modelo adotado por Pinker é descrito pelo próprio autor:

\footnotetext{
${ }^{1}$ Jjprmaçosta. Doutoranda PGIE/UFRGS, coordenadora Núcleo de Multimídia e Ensino a Distãncia da Escola de Engenharia da UFRGS/Grupo de Estudos Tecnológicos. A referida resenha integra projeto de pesquisa da autora, já aprovado, para obtenção de título de doutor.

${ }^{2} \mathrm{O}$ autor foi utilizado como quadro teórico para a interpretação de possíveis elementos relacionados ao perfil cognitivo dos engenheiros e dos projetos de Engenharia como ferramentas didático-pedagógicas para atender a esse perfil.
}

V. 2 № 1, Março, 2004 
“(...) a mente é um sistema de órgãos de computação, projetados pela seleção natural para resolver os tipos de problemas que nossos ancestrais enfrentavam em sua vida de coletores de alimentos, em especial entender e superar em estratégias os objetos, animais, plantas e outras pessoas. (...) A mente é o que o cérebro faz; especificamente, o cérebro processa informações, e pensar é um tipo de computação." (Pinker, 2000, p. 32)

\section{causal}

Inteligência: processamento de símbolos de naturezas informacional e

A inteligência humana para Steven Pinker (2000) não provém de um campo de energia, de vibrações magnéticas ou de qualquer outra natureza sobre-humana. Provém da capacidade do cérebro humano de funcionar exatamente como um computador neural, processando informação. Essas informações estão na forma de símbolos configurados em bits de matéria (neurônios), cujo conteúdo é transmitidos na forma de padrões de conexão e de padrão de atividade dos neurônios. Por isso a informação não se perde quando muda de suporte físico, como por exemplo uma informação oral, que passa de atividade neural a padrões sonoros, transmitidos pelo ar até a membrana auditiva onde muda novamente de suporte físico e acaba retornando ao processamento do cérebro, através da atividade neuronal.

Os símbolos formados por esse mesmo cérebro-mente não são apenas o resultado de uma inscrição/representação interna, a partir dos sentidos. São símbolos que podem conter, além da informação representacional, propriedades causais, o que significa que contêm informações e simultaneamente fazem parte de uma cadeia de eventos físicos, ou seja, podem gerar informações e/ou ações. Então, os bits de informação processados pelo cérebro-mente humano podem acionar outros bits componentes de símbolo, produzindo sentido: validação ou não de informações (verdadeiras ou falsas, que vão formar o conjunto de crenças do indivíduo); ou podem acionar bits conectados com músculos, resultando em movimento.

Isso torna a computação mental complexa e viabiliza a combinação de processamentos, envolvendo, por exemplo, que um símbolo processado, sob determinado conjunto de regras, acione um evento mecânico (ou eletrônico, como acontece com um computador real, ou com um autômato programável para executar funções, ou, como pensava Alan Turing ${ }^{3}$, em 1937, aconteceria com um processador de símbolos capaz de ler símbolos e operar a partir de um conjunto fixo de regras).

"Nossa máquina racional deve sua racionalidade a duas propriedades unidas uma à outra na entidade que denominamos símbolo: um símbolo transmite informação e faz com que coisas aconteçam. Quando as próprias coisas causadas transmitem informação, chamamos todo o sistema de processador de informações ou computador”. (p. 78)

\footnotetext{
${ }^{3}$ A chamada Máquina de Turing, ponto de partida para a idéia de processamento neural de símbolos de Pinker, é uma espécie de computador universal, que parte da idéia de que qualquer cálculo poderia ser realizado por uma máquina que siga instruções (programação, algoritmos).
} 
Trata-se de um paradigma estruturado sobre a chamada Teoria Computacional da Mente ${ }^{4}$, que supõe para o funcionamento da mente humana as naturezas do processo computacional de informações na forma de símbolos. Este processo computacional está associado à capacidade do cérebro humano de representação mental do conhecimento (representação visual, fonológica, gramatical e em uma linguagem mental interna do ser humano), em camadas complexas e inter-relacionadas de redes associativas de significados.

Esse sistema biológico-informacional peculiar da espécie humana também está equipado com sistemas de regras para processamento, que seriam infinitamente mais flexíveis do que aquelas regras que compõem qualquer tipo de programação computacional convencional, e que viabilizam não apenas categorizações do conhecimento precisas e/ou probabilísticas (Fuzzy), mas também lógicas abstratas como, por exemplo, a que permite ao ser humano reconhecer um rosto ou mesmo a noção de individualidade. Esse poderoso software geneticamente aperfeiçoado também funciona de forma a conservar, na representação mental, as relações preservadoras de verdade exatas ou probabilísticas que formaram a suposta relação verdadeira observada na realidade, da primeira vez que o cérebro operou sobre aquele símbolo.

"Esses eventos constituem uma computação, pois o mecanismo foi arquitetado de modo que, se a interpretação dos símbolos que acionam a máquina for uma afirmação verdadeira, a interpretação dos símbolos criados pela máquina também será uma afirmação verdadeira." (Idem, p. 88)

\section{Operações mecânicas e/ou conceituais: valor da informação é construção social ou individual}

A computação mental não implica seqüência de passos distintos, nem que os símbolos estejam completamente presentes ou ausentes, diz Pinker. Também não implica que é garantida uma resposta certa em tempo definido, nem que se possa definir o que está completamente certo ou errado, o que dá uma noção da flexibilidade do sistema. O computador neural, segundo ele, opera com muitos elementos ativados em graus de probabilidades de que a afirmação seja verdadeira ou falsa, permitindo ao ser humano lidar com ambigüidades e complexidades. Agrega inteligência ao sistema operando para alterar os níveis de atividade para registrar a ocorrência de novas probabilidades, que possam validar, invalidar ou alterar pesos probabilísticos inscritos no sistema.

A matriz de agregação de inteligência a esse sistema também se dá pela manipulação de símbolos. Da primeira vez que for manipulado, o símbolo implicará como verdade os padrões posteriores, e esse tipo de informação vai constituir a base do conjunto de crenças do indivíduo, que ficará inscrito, portanto, no repertório mental (representado através de padrões integrados aos bits/neurônios). Essa operação de abastecimento de repertório vai viabilizar que o cérebro suponha um mundo determinado onde aquele universo computacional é plausível e componha a interpretação sobre o mundo, inclusive completando informações inexistentes na

\footnotetext{
${ }^{4}$ A Teoria Computacional da Mente se baseia em idéias expressas pela primeira vez por Alan Touring e pelos cientistas da computação Alan Newell, Herbert Simon e Marvin Minsky e pelos filósofos Hilary Putnam e Jerry Fodor (Pinker, 2000).
}

V. 2 № 1, Março, 2004 
informação processada (deduções, inferências). Observe-se nesse ponto a comparação possível com a observação científica dos fenômenos, constituindo suposições sobre os fenômenos da realidade e processando-as através da lógica matemática, para validar ou invalidar repertórios que vão se constituir na base de modelos ou teorias sobre a realidade.

Dentro dessa concepção, Pinker sintetiza os elementos do processo e os integra na lógica de objetivo-estratégia: "Crenças são inscrições na memória, desejos são inscrições de objetivos,pensar é computação, percepções são inscrições acionadas por sensores, tentar é executar operações acionadas por um objetivo." (Pinker, 1989, p. 90)

A síntese acima permite ao autor separar o processo puramente computacional do cérebro, sua funcionalidade, das construções culturais produzidas através desse processamento, ao longo do tempo, que resultaram em conjuntos complexos de crenças, inscritas na memória de longa duração do ser humano e de sua cultura, que se reproduzem como verdades ou falsidades, dependendo da cultura e dos instrumentos institucionais de validação dessas crenças. Pinker não discute a importância da cultura, nem o seu papel constituinte no sistema de crenças. Apenas separa o valor (suposto) comumente associado ao conjunto de crenças, através dos sistemas que as institucionalizam, como as ciências sociais, a filosofia, as religiões ou as ideologias, da sua natureza ontológica. As verdades culturais não são verdades ontológicas, justificáveis por uma natureza superior ou metafísica do espírito humano. São informações inscritas (na forma de padrões de bits) na memória, adquiridas através do processamento inteligente de informações representadas mentalmente no cérebro-mente através de símbolos complexos e combinatórios, segundo uma lógica, ou um sistema de regras de natureza exata (se...então), probabilística (fuzzy) ou mesmo abstrata, mas identificável diz ele, e característica do tipo de funcionamento do software mental humano. Esse processo faz parte da agregação de inteligência ao sistema processador formado pelo cérebro-mente neural-computacional humano.

Os objetivos criados pelas necessidades relativas ao meio onde se inserem os indivíduos serão inscritos nos seus sistemas individuais, em uma suposta coluna desejos, evidentemente alimentada pelo conjunto de crenças já existentes e mediado pelas emoções, que são, para o autor, o instrumento de informação (a partir dos sensores-sentidos) definidores da prioridade dos objetivos ${ }^{5}$ e do impulso para executálos, tantas vezes quantas forem necessárias ou possíveis (tentativas). Para Pinker, " $o$ cérebro é um instrumento de precisão que permite a uma criatura usar informações para resolver os problemas apresentados por seu estilo de vida" (idem, p. 197), uma compreensão extremamente oportuna para remeter à Engenharia como instrumento de operação sobre as necessidades práticas, de qualquer tempo histórico ou cultural.

A funcionalidade do sistema inteligente de processamento de informações descrito por Pinker depende, resumidamente, de informações representadas na forma de proposições lógicas, operadas de forma lógica, integradas a camadas complexas de redes associativas conceituais que permitem o intercâmbio de propriedades entre conceitos (categorizações, que viabilizam deduções e inferências), da forma como são modelados os sistemas de redes neurais (usados em sistemas de Inteligência Artificial). Além disso, depende também de operadores das relações definidas pelo sistema, que

\footnotetext{
${ }^{5}$ Pinker define a emoção como o gatilho que define a prioridade, a urgência dos objetivos e a prontidão do corpo para aplicar estratégias de resoluções, sejam elas a fuga ou as infinitas nuances possíveis (para os humanos) de enfrentamento das situações. "As emoções - escreve ele - são mecanismos que ajustam os objetivos de mais alto nível do cérebro. Uma vez desencadeada por um momento propício, uma emoção desencadeia a cascata de sub-objetivos que denominamos pensar e agir." (Pinker, 1989, p. 394)
} 
Pinker designa demons, ou agentes não necessariamente inteligentes, com funções relacionadas ao abastecimento do sistema (consulta ao banco de memória, comparação de propriedades entre conceitos, informação de inferências ou de ações ao conjunto do sistema, etc.). Define, portanto, etapas conceituais e outras etapas puramente mecânicas, operacionais, no conjunto do processamento.

\section{Mecanismos inatos para viabilizar processamento modular e estruturação do conhecimento}

O processo descrito por Pinker é viável no contexto da chamada mente modular ${ }^{6}$. Os símbolos referem-se às coisas do mundo, porque são gerados pela informação sobre o mundo que chega através dos sentidos. Os bits que codificam os símbolos são processados através de módulos mentais especializados em cada uma das áreas de interação com o mundo (visão, audição, linguagem, etc.), em padrões e conexões que são ditadas pela própria programação genética. "A mente é organizada em módulos ou órgãos mentais, cada qual com um design especializado que faz desse módulo um perito em uma das áreas de interação com o mundo. A lógica básica dos módulos é especificada por nosso programa genético”(p. 289).

Para operar esse computador neural, cuja programação vem descrita pela genética humana e pelo processo evolutivo de seleção natural, em busca de soluções adaptativas, o modelo mental de Pinker opera a partir da idéia de modularidade no processamento de informações e também na estruturação mental do conhecimento. Assim, a partir de um conjunto finito de elementos, como por exemplo as unidades sonoras discretas, que se articulam em módulos sonoros, que são as palavras, estas vão se combinar, segundo um conjunto de regras estabelecidas no próprio software mental, potencializando infinitamente as possibilidades de representação.

Da mesma forma, conjuntos de módulos do tipo geon ${ }^{7}$ e suas características de junções se combinaria para viabilizar a representação de um número ilimitado de objetos do mundo. E um estoque finito de notas e conjuntos de regras para sua combinação viabiliza a representação de um número infinito de músicas. A mesma idéia de módulos, portanto, vai compor o modelo descrito por Pinker para o que seriam as unidades básicas de conhecimento, em todas as áreas: módulos ligados a módulos, partes dentro de partes em infinitas combinações, segundo regras definidas pelo software mental humano, compreendidas no universo da lógica, das operações matemáticas, da categorização objetiva e difusa (Fuzzy) e da operação de probabilidades.

Para chegar a esse processamento modular de informações e de estruturação do conhecimento, o computador neural humano fará uso de um conjunto de possibilidades de processamento (softwares) já instaladas desde o nascimento, ou o que o autor chamou de mecanismos mentais inatos, que viabilizariam o uso das capacidades de processamento do mundo em todas as áreas do conhecimento.

Entre esses mecanismos inatos estaria a capacidade de linguagem (que Pinker considera um instinto), capaz de representar mentalmente os símbolos relativos às informações de todas as naturezas. A idéia foi desenvolvida pelo linguísta Noam Chomsky e define uma espécie de gramática mental (o mentalês), muito mais sintética

\footnotetext{
${ }^{6}$ O conceito de mente modular foi proposto por Jerry Fodor, em 1983, supondo a constituição da mente como um conjunto de módulos especializados em processamentos de diferentes tipos de inputs, com um módulo processador central integrador de todos eles (conforme Pinker, 1988).

${ }^{7}$ Géons - denominação de unidades geométricas simples (modelos ou módulos básicos para qualquer informação visual) supostamente usadas pelo cérebro humano no reconhecimento visual de formas. 
do que as línguas naturais, desprovida de ambigüidades, a qual se desenvolveria nas crianças independentemente de qualquer educação formal, de forma espontânea. Também estruturado com base em módulos combináveis de forma compositiva ${ }^{8} \mathrm{e}$ recursiva, com base em regras lógicas, esse mentalês seria uma das formas de representação mental conceitual, responsável inclusive pela organização das imagens mentais, as quais seriam indexadas na memória de longo prazo pelo seu conteúdo conceitual (como legendas descritivas, para indexação) e não representacional.

Além da capacidade instintiva de representação mental, a programação genética daria ainda ao ser humano uma teoria da mente inata, ou uma psicologia intuitiva. Através desta intuição, mesmo os bebês tem expectativas sobre os comportamentos dos que o rodeiam, trabalhando com possíveis antecipações do que os outros vão fazer. $\mathrm{O}$ desenvolvimento desse processo, dirá Pinker, vai permitir que os adultos estabeleçam comportamentos em função das expectativas e das previsões que farão sobre o comportamento dos demais, o que será feito com base no seu próprio conjunto de crenças.

Um outro mecanismo inato instrumentador do processamento inteligente do computador neural dos homo-sapiens seria uma física intuitiva, ou uma compreensão intuitiva da noção de objeto e causação, presente mesmo em criança que conseguem compreender partes que se movem juntas, trajetórias contínuas, objetos coesos e movimento para contato. É a base do que será depois constituído formalmente como o conhecimento da Física.

Além da física intuitiva, haveria também uma matemática intuitiva, que torna viável a percepção infantil da noção de quantidades, que vão evoluir para seriações e fundamentar o conhecimento matemático formal. A natureza da Matemática formal, diz Pinker, diferentemente da matemática intuitiva, é complexa, desenvolvendo-se com lentidão ou mesmo não se desenvolvendo em alguns indivíduos, porque os indivíduos não tiveram o acesso ao conhecimento formal de forma cumulativa. A Matemática formal, a propósito, seria impiedosamente cumulativa, segundo o autor, o que seria a razão principal das dificuldades dos alunos de cálculo: não processaram toda a acumulação necessária, começando da contagem de 1 a $10 \ldots$

As pessoas terão vários modos de conhecer e operar sobre a realidade, diz Pinker, estabelecendo teorias intuitivas adaptadas às suas vivências, sejam elas relacionadas a objetos, animais, plantas, artefatos, outras mentes, laços familiares e responsabilidades sociais. Isso será feito através de agrupamento de propriedades relativas a esses conjuntos de elementos e suas co-relações, num processo de categorização, que vai permitir a estruturação das redes de significados e as operações de inferências (deduções baseadas na suposição do que não está explicito) referentes ao mundo suposto onde os fenômenos categorizados estão ocorrendo. "Elas manejam instrumentos de inferência como os elementos da lógica, aritmética e probabilidade" (idem, p. 373), produzindo pensamentos que, por sua vez, "são combinatórios (partes simples combinam-se) e recursivos (partes simples podem ser embutidas em partes)" (p. 380). Com esse tipo de processamento, amplificam-se de maneira infinita os instrumentos mentais humanos de aquisição e processamento de conhecimento.

Através desse tipo de estruturação do conhecimento, o aprendizado cultural, ou o que chamou de compreensão educada da realidade é formada por um "enorme dispositivo de partes dentro de partes. Cada parte é construída com módulos mentais

\footnotetext{
${ }^{8}$ Compositividade $=$ capacidade de representação ser construída com partes e ter um significado que provém do significado das partes e do modo como elas são combinadas (ex. línguas humanas)
} 
ou modos de conhecer básicos (softwares) que são copiados, têm seus conteúdos originais (coletar, caçar) apagados, são conectados a outros modelos e embalados em partes maiores, as quais podem ser embaladas em partes ainda maiores, sem limites" (Idem, p.380).

Computação mental de informação através de símbolos e registro de probabilidades, modularidade no processamento e na estruturação do conhecimento e mecanismos inatos de compreensão e representação do mundo serão os elementos fundamentais que caracterizam o pensamento do autor, para efeito dessa pesquisa. Se terá como universo conceitual, portanto, no qual deverá caber o funcionamento da mente do engenheiro e a execução de seu trabalho, a definição de Pinker de que a mente humana é um computador neural programado pela seleção natural para processar de forma inteligente as informações sobre o meio, que opera através de módulos especializados em informações de várias naturezas, combinando símbolos e módulos de símbolos, segundo regras lógicas formais, probabilísticas ou abstratas, geneticamente selecionadas, para operar sobre os problemas apresentados pelo meio no qual está inserido. Um mapa conceitual descrevendo os principais elementos do modelo de mente humana descrito por Pinker é apresentado a seguir, a título de resumo.

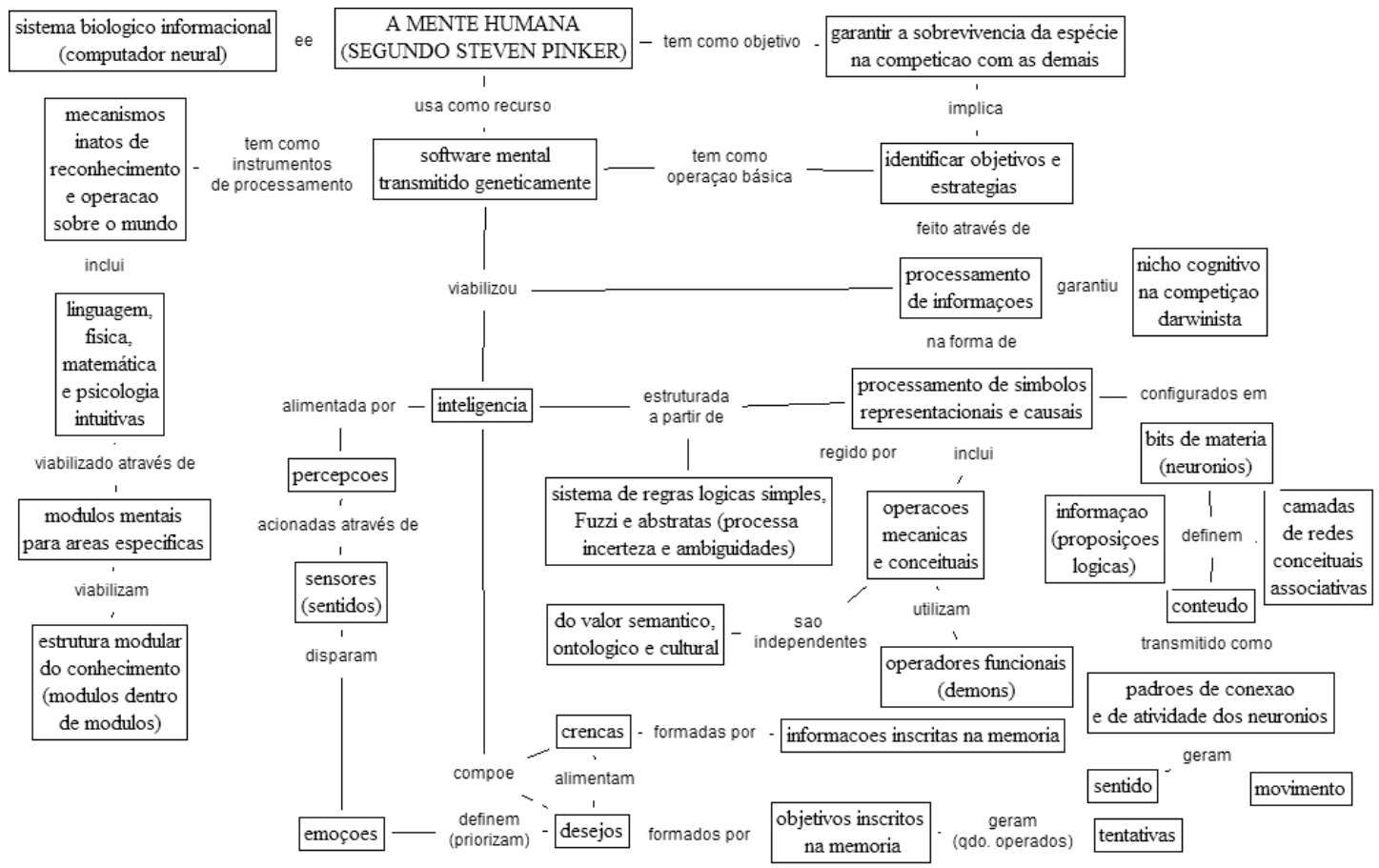

Fig. 1 - Mapa conceitual resumindo modelo mental sugerido por Pinker 